\title{
Criando Pontes entre Identidade, Cultura e Nação: O Uso de Freire no Intercâmbio Estudantil em Gana
}

\author{
H. LESLIE STEEVESa \\ University of Oregon, School of Journalism and Communication. Eugene - OR, EUA
}

\section{RESUMO}

Este ensaio mostra como a pedagogia de Paulo Freire tem informado um intercâmbio anual imersivo e de longa duração de estudantes de jornalismo e comunicação da Universidade de Oregon, EUA, em Gana, África Ocidental. Os alunos são diversos por classe econômica, identidade racial e étnica, gênero, sexualidade, deficiência e formação cultural. Eles são duplamente desafiados a viver juntos e a trabalhar em diferentes estágios em um ambiente cultural desconhecido, ao lado de ganeses, enquanto completam tarefas e atingem resultados de aprendizagem do programa. Os conceitos e métodos de Freire buscam quebrar barreiras entre professores e alunos e capacitar todos os participantes ao mesmo tempo que os engajam na formação educativa.

Palavras-chave: Identidade, cultura, Paulo Freire, Gana, intercâmbio estudantil

\section{ABSTRACT}

This essay shows how Paulo Freire's pedagogy has informed a long-running, immersive annual excursion of the USA University of Oregon journalism and communication students to Ghana, West Africa. The students are diverse in many ways: by economic class, racioethnic identity, gender, sexuality, disability, and cultural background. They are doubly challenged to live together and to work in separate internships in an unfamiliar cultural environment alongside Ghanaians, while also completing assignments and meeting program learning outcomes. Freire's concepts and methods sought to break down barriers between teachers and students and empower all participants while engaging in literacy training.

Keywords: Identity, culture, Paulo Freire, Ghana, student excursion
Professora e Reitora Associada de Pós-Graduação e Pesquisa na University of Oregon. Orcid: https:// orcid.org/0000-0002-1846-1003. E-mail: lsteeves@uoregon.edu 


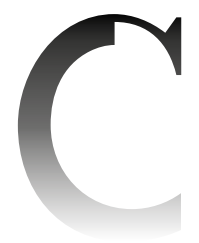

1 A autora usa o termo em inglês, que se traduz literalmente por pessoas negras, indígenas e de cor. Entendemos que essa tradução literal não dialoga de maneira fiel com o conjunto de identidades e lutas antirracistas no Brasil, nem em alguns outros países. Por isso, preferimos manter o termo BIPOC no decorrer do texto, para preservar o sentido e a referência que pertencem ao manuscrito original, elaborado pela autora, destacando que o presente emprego do termo está associado com o contexto de lutas no Estados Unidos, país em que o caso analisado está situado (N. da T.).

\section{INTRODUÇÃO}

$\mathrm{E}$ M TODAS AS áreas acadêmicas, houve uma maior e necessária ênfase nas inter-relações globais. Eventos geopolíticos das últimas décadas (notadamente os ataques terroristas de 11 de setembro), a globalização transnacional, as mudanças climáticas e, recentemente, a pandemia de covid-19 expuseram nossa interdependência global, bem como disparidades no acesso a recursos vitais. Além disso, em muitas nações, há demandas pela diversidade nas organizações, incluindo faculdades e universidades. Nos Estados Unidos, movimentos como o Black Lives Matter (BLM) têm adicionado urgência ao enfrentamento de duradouras formas de injustiças raciais, étnicas etc. A ascensão da retórica e políticas xenófobas e anti-imigratórias mostra a conexão inseparável entre o preconceito e a opressão, doméstica e internacional, mas também, por vezes, tem colocado preocupações domésticas dos BIPOC ${ }^{1}$ em oposição às de novos cidadãos e não cidadãos, complicando ainda mais os movimentos de justiça social.

É nesse complexo contexto que programas de educação experiencial, que imergem os alunos em uma cultura desconhecida e implementam as percepções e pedagogias de Paulo Freire, podem ser eficazes, até mesmo transformadores, na formação das ações e escolhas de curto e longo prazo dos estudantes. Este ensaio, portanto, teoriza e ilustra como os conceitos de Freire se aplicam em um programa de estudo no exterior, que acontece há duas décadas, levando estudantes da University of Oregon (UO), nos Estados Unidos, para Gana, na África. Os alunos são diversos e devem trabalhar em equipe, mas também colaborar com os ganeses em ambientes profissionais de mídia.

Neste ensaio, primeiro, resumo os aspectos da pedagogia de Freire que são fundamentais para esse programa, seguido por um panorama dele. Depois, apresento exemplos, mostrando a evolução do crescimento dos alunos e instrutores em três áreas temáticas sobrepostas: classe econômica e poder - por exemplo, o poder de viajar e representar; identidade e experiência - por exemplo, gênero, raça e deficiência; e cultura - descrevendo diferenças nas normas de mídia e religião.

\section{PEDAGOGIA DE FREIRE}

O programa Media in Ghana (Mídia em Gana) da UO é baseado em conceitos da aprendizagem experiencial e da pedagogia crítica desenvolvidos por Paulo Freire em suas muitas publicações, especialmente em sua obra magna, Pedagogia do Oprimido (1970). Em seu trabalho com adultos em processo de alfabetização nos anos 1960, Freire buscou quebrar as acentuadas barreiras de identidade e cultura entre professores e alunos e empoderar todos os participantes, 
ao mesmo tempo que os alfabetizava; portanto, eles são altamente pertinentes a um programa como o Media in Ghana. Os conceitos freirianos fundamentais para o programa incluem: o caráter relacional da opressão; a historicidade; a práxis; uma rejeição da educação bancária em favor da educação problematizadora; o diálogo; e uma meta de empoderamento.

Com base na teologia da libertação cristã, por exemplo, de Teilhard de Chardin², Freire (1970) assumiu que a libertação de formas de opressão internas e externas é uma qualidade definidora da vida humana, necessária para o crescimento. A partir de Marx, Lênin e outros, ele via a pobreza como resultado de estruturas de classe sustentadas pelo capitalismo como uma forma central de opressão. Também argumentou que os opressores são tão oprimidos quanto suas vítimas, porque seus atos de controle são desumanos para todos os envolvidos. No entanto, a liberdade da opressão não é adquirida e requer luta e compromisso.

Freire (1970) conceitua a prática da liberdade como práxis, "reflexão e ação sobre o mundo para transformá-lo" (p. 36). Isso pode ser realizado por meio do diálogo emancipatório, exigindo amor, humildade, empatia e esperança (Suzina \& Tufte, 2020). A práxis é limitada pelo contexto histórico ou pela historicidade, ou seja, as maneiras pelas quais a história e a cultura dialeticamente moldaram os seres humanos e, ao mesmo tempo, os humanos moldam o devir da história e da cultura. As restrições históricas à práxis variam; portanto, os aprendizes evoluem de forma diferente por meio da luta (Freire, 1974, pp. 4-5).

Freire (1970) defende ainda que a práxis não é possível por meio de formas tradicionais de "educação bancária", em que um instrutor fornece conteúdo para os alunos reterem. Ele argumenta que a educação bancária é uma forma de dominação que submerge a consciência, inibindo o poder criativo (pp. 67-68)3. Ele é a favor da "educação problematizadora", na qual professores e alunos são "coinvestigadores críticos em diálogo" e estão dispostos a reconsiderar visões prévias à medida que refletem sobre as perspectivas dos outros (p. 70). As metodologias problematizadoras incluem a observação participante pelos educadores; a definição de problemas na linguagem dos alunos; a análise das causas dos problemas, a busca por novas palavras e imagens para entendê-los; a modelagem de comportamentos de risco; o estímulo a ideias para soluções e ações; e a reflexão crítica e crescimento (Freire, 1974, 1998).

O objetivo de Freire (1974) é a conscientização, ou seja, "o desenvolvimento do despertar da consciência crítica” (p. 15). À medida que os participantes despertam, seu silêncio e inação são substituídos pela "transitividade crítica", que se caracteriza pelo aumento da profundidade na análise de problemas, pela prática do diálogo versus polêmicas, pela abertura a diferentes pontos de vista, pela recusa
2 Para os fundamentos filosóficos e teológicos do pensamento de Freire, ver Thomas (1994) e Melkote e Steeves (2015).

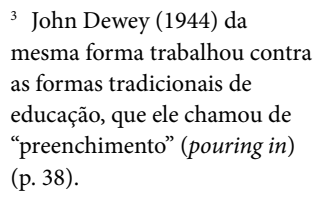

3 John Dewey (1944) da mesma forma trabalhou contra as formas tradicionais de educação, que ele chamou de "preenchimento" (pouring in) (p. 38). 
${ }^{4} \mathrm{O}$ Journal of Experiential Education possui inúmeros estudos de caso de excursões experienciais que também se baseiam em Freire.

${ }^{5}$ Ver Steeves (2006) para uma história detalhada. em transferir a responsabilidade, por uma rejeição das soluções passivas e pela capacidade de enxergar a validade nas abordagens dos outros (p. 15).

Desde que Freire esboçou esses conceitos e métodos, inúmeros estudiosos e professores os usaram para implantar pedagogias participativas, integralmente colaborativas, engajadas, críticas, empoderadoras e baseadas na comunidade (ver Giroux, 1988; hooks, 1994; Kolb, 1984; Shor, 1992). Além disso, o pensamento freiriano tem informado outros que conduzem viagens imersivas, particularmente aquelas que oferecem oportunidades de aprendizagem em serviço ou voluntariado ${ }^{4}$.

Em um enquadramento útil para a prática de comunicação para o desenvolvimento, mas igualmente relevante para programas educacionais como o intercâmbio estudantil no exterior, Tufte e Mefalopulos (2009) definem quatro níveis de participação: participação passiva, ou seja, meramente informar os beneficiários das decisões; participação por consulta, solicitando feedback periódico sem compromisso de agir a partir dele; participação por colaboração, que inclui componentes de comunicação horizontal, dando aos interessados primários oportunidades de contribuir via discussão e análise; e participação empoderada, com diálogo durante todas as fases do processo, do planejamento à avaliação, de tal forma que todos os interessados tenham voz significativa (pp. 6-7). A participação empoderada é consistente com as crenças de Freire. Acredito que esses níveis são úteis para refletir sobre o programa Media in Ghana nas seções subsequentes.

\section{MEDIA IN GHANA}

O programa acontece em Gana, África Ocidental. A estabilidade política de Gana, a economia emergente, a presença vibrante da mídia, a experiência acadêmica na University of Ghana e em outras faculdades e universidades e o uso generalizado do inglês como língua nacional tornam esse país um local de estudo atraente para intercâmbio de estudantes de mídia e jornalismo dos EUA. O papel de Gana no comércio transatlântico de escravos e no Movimento dos Direitos Civis dos EUA agrega interesse, especialmente para os estudantes BIPOC. Gana também continua sendo um país em desenvolvimento, com barreiras logísticas, limitações de recursos e diferenças culturais que representam um contexto desafiador e gratificante para a aprendizagem. O Media in Ghana começou em 1999 e continua até hoje $\mathrm{e}^{5}$.

O programa evoluiu ao longo dos anos como resultado do feedback estudantil, da experiência do instrutor e do aumento da demanda, embora algumas características tenham permanecido constantes. Os candidatos são 
selecionados por meio de redações, verificações de referência, registros de conduta e entrevistas. Alguns conhecimentos de Gana (mostrando iniciativa), entusiasmo, uma atitude flexível, maturidade e habilidades adequadas para um estágio em mídia são considerados.

Os alunos vivem juntos em uma casa, embora saiam diariamente para um estágio individualmente designado. Os estudantes também fazem um curso que começa na primavera, antes da partida. Embora leituras sobre história, cultura, política e mídia de Gana sejam oferecidas e frases básicas na língua local mais difundida (Asante Twi) sejam ensinadas aos alunos, um objetivo importante é simplesmente se familiarizar. Aqui, a noção de historicidade de Freire é importante para reconhecer que cada aluno e instrutor começará em um lugar diferente e progredirá de forma variada. As estratégias dialógicas para reduzir as lacunas entre instrutores e alunos são importantes, pois a experiência de aprendizagem no local será colaborativa, exigindo uma base de confiança.

Durante nossa primeira semana na capital de Gana, Accra, continuamos o curso de orientação através de discussões em grupo, bem como reuniões com estudiosos e profissionais da mídia ganesa. Também fazemos excursões locais. Os estágios se iniciam na segunda semana do programa e se estendem por cinco semanas, em tempo integral, com excursões de fim de semana fora de Accra. Os alunos devem manter um diário de bordo de mídia, registrando suas observações relacionadas à comunicação dentro e fora de seus estágios. Eles também devem escrever um artigo usando fontes primárias, isto é, entrevistas com ganeses. Essas atribuições requerem observação crítica e reflexão, conforme teorizou Freire. Uma vez no local, as estratégias de definição dos problemas de Freire são essenciais, já que os alunos se encontram em um ambiente desconhecido com tarefas a serem feitas e, portanto, precisam compreender, ou seja, problematizar suas novas realidades antes de identificar soluções (Goulet, 1974, p. ix).

Uma forma significativa pela qual o programa se desenvolveu é no número e na diversidade de alunos participantes. Nos primeiros anos e com poucas opções de ajuda financeira, os grupos eram pequenos, com até nove estudantes, quase todos brancos, do sexo feminino e de origem de classes com mais recursos. Mesmo assim, tornou-se evidente que a dinâmica de grupo era uma parte significativa da viagem, e os alunos que normalmente não seriam amigos desenvolveram laços profundos e duradouros. Com o passar do tempo, as bolsas se materializaram e as inscrições aumentaram, comecei a formar grupos maiores (15-20) e mais diversos - por gênero, idade, sexualidade, identidade racial e étnica, classe, deficiência e muito mais, exigindo que os alunos enfrentassem hierarquias cotidianas de opressão, dentro e fora do grupo. A evidência de adequação para a viagem - atitude flexível, entusiasmo, maturidade - permaneceu essencial. No entanto, como para os candidatos iniciais, 


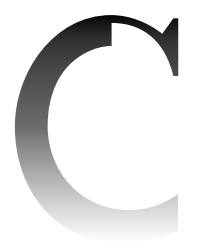

${ }^{6}$ Meu colega Sung Park criou o blog. Ver: https://ghana. uoregon.edu.

7 Meu colega Chris Chavez apresentou o componente do projeto da equipe, começando pelo primeiro cliente, Alliance for Reproductive Health Rights (ARHR). Ver o blog para ativos criados, por exemplo: https:// ghana.uoregon.edu/category/ arhr-video/.

Os resultados atuais de aprendizagem indicados são: conhecer a história colonial e pós-colonial africana básica; compreender eventos históricos compartilhados entre ganeses e norte-americanos relacionados ao comércio transatlântico de escravos, ao Movimento dos Direitos Civis dos EUA e ao movimento de independência de Gana; entender a história e a evolução da mídia de Gana e os desafios atuais/constantes das organizações de mídia ganesas; melhor entender, apreciar e respeitar a diferença cultural e a diversidade; ser capaz de viver e trabalhar profissionalmente em uma cultura desconhecida; ser capaz de avaliar criticamente as representações da África na mídia ocidental.

sempre foi considerada a ordem de chegada e, como a maioria se inscreve no prazo, não é difícil considerar a diversidade e, ao mesmo tempo, ser justo com todos os candidatos. A partir de então, isso enriqueceu a experiência de todos, já que estamos duplamente imersos em uma cultura desconhecida e, também, com companheiros diversos de equipe. Além disso, busquei financiamento para incluir colegas como coinstrutores/participantes, com ênfase naqueles de origens sub-representadas.

Em 2011, um colega criou o blog do programa, e os alunos devem postar periodicamente ${ }^{6}$. Oblog oferece um espaço para compartilhar experiências e mostrar trabalhos. Ao mesmo tempo, o feedback de pares e de leitores sobre as postagens facilitou o diálogo na exposição de diferenças. A ascensão das mídias sociais e das postagens dos estudantes em plataformas como Facebook, Twitter e Instagram têm proporcionado oportunidades adicionais. Além disso, durante vários anos, entre 2015 e 2019, os alunos formaram equipes para conseguir recursos para grupos locais sem fins lucrativos. Os alunos com estágios de menor demanda tinham, assim, outro modo de se envolver com os ganeses e garantir material de portfólio, e todos tinham outro caminho para aprender e contribuir, conforme o tempo permitido ${ }^{7}$.

Outra mudança está nos resultados de aprendizagem do programa. Alguns são predefinidos no currículo, estabelecido no que pode parecer definição de cima para baixo, como no menor nível de participação passiva de Tufte e Mefalopulos (2009). No entanto, de fato, os resultados de aprendizagem evoluíram ao longo dos anos, em resposta ao feedback via participação consultiva ${ }^{8}$. Mais significativamente, a forma de avaliação dos resultados de aprendizagem varia de acordo com o contexto do participante e do grupo. Os resultados de aprendizagem mais importantes não estão listados, ou seja, aqueles relacionados ao aumento da consciência e ao crescimento. Os alunos geralmente vêm ao programa em busca de crescimento pessoal, escrevem e tornam visíveis suas percepções pessoais durante e após o programa. O objetivo de conscientização de Freire, ou seja, exigir consciência autorreflexiva da diferença e do privilégio é primordial. Minha esperança é que os alunos saiam com uma consciência aprimorada das relações humanas e das semelhanças, um senso de crescimento, apreço por diferentes visões de mundo e compromisso de agir contra a injustiça.

Em seguida, discuto exemplos de como os conceitos de Freire se aplicam nesse programa e levaram a percepções e ações em três áreas relacionadas à diferença: a classe, a identidade e a cultura.

\section{CLASSE E PODER}

Os alunos e instrutores da UO têm o poder de classe e nacionalidade para viajar e experimentar Gana, enquanto poucos ganeses terão essa oportunidade. 
Somos, portanto, desafiados a entender nosso privilégio econômico-político e, ao mesmo tempo, aprender a apreciar melhor a complexidade de Gana, para ler e compor narrativas e imagens que resistam a representações simplistas e incorretas.

Apesar das informações facilmente disponíveis sobre o programa, muitos estudantes são motivados a se candidatar com base em imagens da África como um continente em situação de pobreza que precisa ser salvo. Geralmente, os candidatos escrevem sobre ter escolhido Gana, em vez de um local europeu, em parte pelo desejo de ajudar. O diálogo para mudar sua mentalidade de ajudar para ouvir, aprender e valorizar as relações humanas começa na entrevista inicial, estendendo-se ao longo do programa, nas aulas preparativas e no local. Recursos úteis incluem a palestra de Adichie (2009), "O Perigo da História Única", o ensaio satírico de Wainaina (1992), "Como Escrever sobre a África”, e exemplos atuais de deturpações, como a reportagem "Águas Turvas", da CNN, sobre a suposta escravidão infantil na indústria pesqueira de Gana, que mostra como a persistente retórica da África-como-vítima sustenta um nexo jornalismo-ONG pelo qual jornalistas obtêm histórias de origem local e as ONG recebem exposição e receitas (Amenuti, 2019).

Uma vez no local, e seguindo a orientação, os alunos têm uma consciência ampliada sobre representação. Eles desejam enfatizar matérias positivas e fornecer contexto para as negativas. No entanto, rapidamente aprendem que mesmo representações positivas podem não escapar de leituras hegemônicas. Como exemplo, em 2013, um estudante recém-chegado postou uma foto no Facebook de si mesmo com algumas crianças do bairro com a inocente legenda: "Fiz alguns novos amigos em Gana". Seu irmão repostou com uma nova legenda: "Meu irmão mais velho está em Gana, salvando crianças". O incidente provocou conversas subsequentes sobre a ética da representação e o reconhecimento de que mesmo as histórias mais bem contextualizadas nunca serão perfeitas, e as leituras do público não podem ser completamente controladas. Além disso, estamos todos na curva de aprendizado, e devemos nos permitir cometer erros e seguir em frente.

Em relação à consciência de classe, os alunos se mudam para uma casa compartilhada em um dos bairros mais ricos de Accra; no entanto, em parte para reduzir o custo do programa, a casa não possui ar-condicionado, água quente ou pressurizada, nem wi-fi. Eles resmungam no início sobre o pequeno desconforto e inconveniente, mas então são imediatamente atingidos pela extrema desigualdade econômica em Gana, conforme observam: primeiro, a partir de um onibus com ar-condicionado, que percorre a Grande Accra, e mais tarde em suas atividades diárias. Os estudantes sabem que a pobreza existe nos EUA, mas a maioria pode optar por não a ver. Não é assim em Gana, onde a riqueza
${ }^{9}$ Ver Madison e Steeves (2014, p. 218). 
e a pobreza são evidentes diariamente e eles são obrigados a lidar com a ansiedade que esses encontros rotineiros provocam.

A reação de Catherine após o passeio por Accra, logo após a chegada, é típica:

A excursão parecia perigosamente próxima do turismo de catástrofes. Essa não foi a intenção da visita no veículo automotivo, no entanto, e estou feliz que não nos limitamos apenas aos pontos turísticos dignos de cartão postal. A pobreza é feia, mas fingir que não existe não colocará água limpa em copos infantis ou sistemas de esgoto em comunidades carentes. Saber que as crianças estão queimando nossos computadores descartados pelos seus metais preciosos, que as famílias têm de tomar banho na rua por falta de espaço, que cursos d'água estão entupidos com sacos plásticos e dejetos humanos - a poucos minutos de distância de onde dormimos - me humilha. Espero que este dia nos faça valorizar o que temos, a baixa pressão da água e tudo mais. (Gregory, 2011a, para. 5)

Com o passar do tempo, eles continuam a refletir sobre esses extremos. Depois, Catherine escreveu sobre visitar uma escola em uma comunidade carente, a generosidade dos funcionários em preparar uma refeição para ela, sua tentativa fracassada de comê-la, sua repulsa ao estado do banheiro, e suas reflexões posteriores:

Lutei para identificar e abordar uma mistura de sentimentos: culpa por desperdiçar toda uma refeição na escola, alívio ao escapar das sarjetas abertas de Nima, desgosto pela meca consumista turística de Osu, raiva pelo meu próprio privilégio e sensibilidade delicada.

Em Accra, estou constantemente procurando algum tipo de equilíbrio. Meus dias nunca são "bons”, são sempre uma mistura de muito bom e muito ruim. Oscilo entre emoções, vou da satisfação ao desconforto físico e sigo meu caminho entre a pobreza abjeta e a opulência. Essa é uma terra de contrastes, e meu interior espelha esse tumulto. (Gregory, 2011b, paras. 11-12)

Afinal, os alunos começam a discutir desigualdades não reconhecidas ou ignoradas anteriormente em casa, como Emily escreveu:

Os pobres ganeses estão morrendo por falta de saneamento, mas os americanos também....

Por todo o país, nos Estados Unidos, pessoas pobres e minorias são mais propensas a sofrer pela degradação ambiental, poluição e saúde ruim. ...

A desigualdade entre ricos e pobres está longe de ser apenas um problema africano. Talvez os americanos ricos achem a realidade mais fácil de ignorar - nós nos 
reunimos, em bairros e no trabalho e nos círculos sociais, e dizemos a nós mesmos que a pobreza real está longe. Em Gana, ela te olha na cara. Mas a realidade da situação é mundial e crescente: a menos que mudemos, e rápido, grande parte desta terra se tornará inabitável. Nesse ponto, nossos portões não nos ajudarão muito. (Topping, 2019, paras. 9, 11, 15)

Em seus estágios, os alunos enfrentam restrições de recursos. Embora as sessões preparatórias abordem esses assuntos, as limitações são desafiadoras. Os estudantes devem circular no tráfego pesado em transporte público (minivans adaptadas chamadas trotros) para chegar aos seus locais de estágio ${ }^{10}$. Em comparação com os primeiros anos do programa, os telefones inteligentes agora são onipresentes, e o wi-fi é amplamente acessível; no entanto, o uso de dados da internet é caro e nem todos os lugares oferecem acesso. O ar-condicionado nem sempre está disponível e a energia elétrica é instável. Alguns locais carecem de banheiros ou facilidade de acesso a alimentos, o que exige que os alunos descubram como atender às necessidades básicas e manter-se saudáveis. Além disso, a logística das tarefas cotidianas de trabalho pode ser frustrante (ver O'Leary, 2019a). Com o passar do tempo, a maioria desenvolve um novo respeito pelos trabalhadores da mídia ganesa e o quanto eles são capazes de realizar com relativamente pouco. Os estudantes também se tornam humildes pela imensa gratidão e generosidade de seus supervisores e colegas, mesmo após apenas algumas semanas. Ben, por exemplo, expressou sua grande surpresa, no final do programa, quando os colegas de trabalho da agência de publicidade convidaram a ele e a um estagiário para almoçar, e depois os levaram a uma loja para escolher roupas ganesas (Neal, 2016).

Em 2013, nossos alunos vivenciaram um evento particularmente traumático, que os marcou profundamente - e a mim, como instrutora, também. Numa manhã, antes do amanhecer, quando os alunos ainda estavam dormindo (a segurança também havia cochilado), ladrões entraram em sua casa e roubaram vários laptops, iPhones, câmeras e carteiras. Passamos o dia fazendo o inventário, preenchendo relatórios e lamentando. Mais tarde, parti brevemente para outros assuntos. Quando voltei, os estudantes se reuniram em círculos. Um sugeriu que eles caminhassem e cada um dissesse algo para ser grato. Eles expressaram gratidão um pelo outro e pela experiência de Gana. Também reconheceram que este momento passaria e, um dia, seriam capazes de substituir seus aparelhos, uma opção que a maioria dos ganeses nunca poderia ter. Em grupo, eles discutiram se e como denunciar e enquadrar o roubo em seus estágios e nas redes sociais. Todos os comentários foram comoventes, e houve lágrimas. Antecipei raiva e ameaças de processos judiciais, mas suas reações foram exatamente o oposto, revelando
${ }^{10}$ Para uma excelente visualização de um dia típico de trabalho do estudante, ver o vídeo curto de Higdon (2016). 


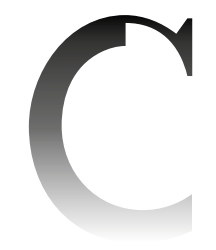

profunda empatia e reconhecendo a oportunidade de aprendizado do momento. A gratidão dos estudantes só aumentou à medida que seus vizinhos e colegas de trabalho ganeses ofereceram apoio e se desculparam por seu país. Carson perdeu seu iPhone, laptop, todas as fotos e toda a dissertação de mestrado. Ele escreveu:

Minhas conexões com meu mundo, minha casa e meu povo tinham sido cortadas. Eu me senti paralisado, e não foi por causa do valor monetário dos dispositivos, foi por causa de tudo que eles representavam e possuíam. Assim, nos dias seguintes, comecei a ver as coisas pela primeira vez. Reconheci momentos que antes tinham passado sem observação e identifiquei coisas que não é possível ver se você não está realmente olhando. Aprendi coisas sobre a vida que teriam sido perdidas em mim, se minha vida não tivesse sido roubada.

Quando você começa a procurar o mal e tudo o que você encontra é o bem, um país cheio de pessoas ansiosas para ajudar, sorrir e dizer olá para estranhos, você aprende sobre o espírito humano.... Quando você vai trabalhar e o escritório faz fila para se desculpar em nome do país deles, todos falando em primeira pessoa como se tivessem roubado você, você aprende sobre o espírito humano. Quando os outros alunos dessa aventura, que tiveram pedaços de sua vida roubados, sentam-se na sala de estar e, juntos, se recusam a deixar que isso defina essa experiência de vida transformadora, você aprende sobre o espírito humano. Quando esse mesmo grupo se torna mais próximo e sorri mais, você aprende sobre o espírito humano. Sem ter sido roubado e perder vários objetos materiais, talvez nunca tivesse aprendido o que vim aqui para tentar entender. Nunca teria adquirido percepções reais sobre o que significa ser humano e o que é

${ }^{11}$ Vários alunos escreveram da mesma forma. Ver, Armor (2013). realmente importante na experiência humana. (York, 2013, paras. 3-4) ${ }^{11}$

\section{GÊNERO, RAÇA E IDENTIDADE INTERSECCIONAL}

Como observado antes, a análise de Freire (1998) da opressão centraliza a classe, geralmente definindo opressores e oprimidos em termos dos que têm e dos que não têm bens materiais. No entanto, alguns de seus escritos fazem adicionalmente, embora brevemente, referência a outros eixos de opressão. "O autoritário, repleto de preconceitos sexuais, raciais e de classe, nunca pode se tornar tolerante sem antes superar seus preconceitos" (p. 42).

O que se pode dizer, por exemplo, de um homem considerado progressista que, apesar de sua fala em favor das classes mais baixas, se comporta como o Senhor sobre sua família, cuja dominância sufoca sua esposa e filhos? O que pode ser dito da mulher que luta pelos interesses daquelas de seu gênero, mas que em casa raramente agradece ao cozinheiro pelo copo d'água? (Freire, 1998, p. 67) 
Inúmeros estudiosos desde Freire têm procurado estender ainda mais seus conceitos para além da classe. Stromquist (2014), hooks (1993, 1994), Melkote e Steeves (2015) e outros argumentam que as pedagogias freirianas são relevantes para ideologias patriarcais, que permanecem fortes globalmente. Outros, como Custódio e Gathuo (2020), utilizaram Freire em relação às ideologias do racismo e do sexismo.

Como as desigualdades são inseparáveis e cheias de camadas, sou a favor de combinar seu trabalho com a interseccionalidade, que argumenta que a opressão raramente é binária e só pode ser compreendida no contexto de muitas intersecções e restrições sociais. Embora Crenshaw (1991) seja frequentemente creditado pelo conceito, outros fizeram argumentos parecidos antes, incluindo pioneiras feministas LGBT, feministas negras, feministas africanas e outras. Frye (1983), por exemplo, usou a metáfora de uma gaiola de pássaros para explicar a opressão: "o pássaro está cercado por uma rede de barreiras sistematicamente relacionadas, nenhuma das quais seria o menor obstáculo ao seu voo, mas que, em suas relações entre si, prendem tanto quanto as sólidas paredes de uma masmorra" (p. 2).

Além disso, e especialmente no contexto do Sul Global, a economia política (via Freire) e a teoria pós-colonial são lentes importantes, pois exigem prestar atenção às estruturas capitalistas geopolíticas sustentadas por divisões entre nações ricas e pobres e classes dentro das nações. O feminismo socialista também é útil na síntese do marxismo e do feminismo, mostrando como o controle dos homens sobre o trabalho feminino é uma característica da maioria das sociedades, evidente na concentração das mulheres em posições de menor remuneração, na insuficiência de creches e apoio à licença parental e de muitas outras maneiras. No contexto dos países em desenvolvimento, a classe composta por estruturas econômicas neocoloniais constitui uma vertente especialmente saliente da gaiola que restringe meninas e mulheres. Um por cento das pessoas do mundo possui quase toda a riqueza mundial e $90 \%$ dos milionários do mundo são homens (Berti, 2018; Credit Suisse, 2019).

Yang (2016) ilustra poderosamente o uso das pedagogias dialógicas de Freire, incluindo círculos de estudo, bem como pedagogias feministas, antirracistas e descolonizantes, por meio de uma lente interseccional, nas folk high schools para adultos na Suécia ${ }^{12}$. Essas escolas, originalmente criadas para adultos sem acesso a escolas públicas, misturam participantes de diferentes origens identitárias e com diferentes níveis de consciência, assim como o Media in Ghana. O estudo de Yang se concentrou no Quarto das Mulheres, uma escola popular exclusivamente feminina, identificada como feminista, para migrantes na Suécia. De acordo com Yang, "a posicionalidade das pessoas migrantes e de seus professores revela as categorias sociais interseccionadas e o poder no trabalho do processo de alteridade" (p. 837).
${ }^{12}$ Rasmussen (2013) discute a história e a pedagogia das folk schools na Dinamarca. 
O gênero e a sexualidade constituem um ponto de discussão constante, antes e durante a viagem no Media in Ghana, especialmente desde que o movimento \#MeToo ganhou ascendência em grande parte do Norte Global, os direitos das lésbicas e gays foram normalizados e o gênero não binário tem sido cada vez mais aceito. Em Gana, tende a haver menos consciência pública a respeito do assédio sexual. A homossexualidade é amplamente tabu e as relações entre pessoas do mesmo sexo são criminalizadas (embora a ação legal seja incomum). As conversações sobre não binariedade e transgêneros não são tão evoluídas como em grande parte do Norte Global. Discutimos essas questões extensivamente, pois nossos alunos precisam estar seguros em Gana, ao mesmo tempo que devem entender que são convidados, com muito a aprender. Também discutimos o contexto histórico relevante, como o impacto da colonização sobre os papéis de gênero (por exemplo, Oyěwùmí, 1997), e revisamos estratégias para lidar com situações comuns - quando e como recuar ou pedir ajuda.

Nossas alunas, especialmente, se veem em inúmeras situações desconfortáveis, pedidos de casamento constantes, convites para encontros e frequentes comentários sobre sua aparência pessoal, que certamente seriam considerados no limite do assédio nos EUA e, ocasionalmente, cruzando essa linha. As estudantes geralmente têm sido capazes de lidar bem com essas situações, às vezes com assistência, e tiveram conversas com ganeses que têm sido mutuamente esclarecedoras. Emily escreveu sobre sua experiência na estação de TV em que estagiou:

os homens me diziam que eu sou bonita, que desejam me levar para casa ou se casar comigo. . . . Muitas vezes, me vi fazendo disso uma piada. . . Em nenhum momento, me senti em ameaçada, mas foi algo estranho e desconfortável.

No entanto, olhando para trás agora, foi realmente uma experiência de aprendizado. Gostaria que não acontecesse? Sim, claro que sim, porque nenhuma mulher deve ser tratada assim. Mas, a partir dessas experiências, pude ter um gostinho de como muitas mulheres são tratadas ao redor do mundo. (Port, 2018, paras. 1-2)

É importante ressaltar que a maioria dos alunos começa a reconhecer que os papéis de gênero são complexos em todos os lugares. Em 2016, Rachel participou de um evento da União Africana, em que Gana recebeu um prêmio de gênero, reconhecendo a liderança na promoção dos direitos econômicos e sociais das mulheres. Mais tarde, ela escreveu:

Em última análise, a vida em Gana me mostrou que o progresso do feminismo não segue um único caminho preestabelecido. As mulheres em uma sociedade podem ter representação sem respeito, ou respeito com limites culturais imutáveis. 
Uma sociedade pode acolher as mulheres no espaço laboral, mas se recusar a reconhecer qualquer mudança de longo prazo nos papéis de gênero. Nada na luta pela justiça social é tão simples quanto "para frente" ou "para trás". Em diferentes contextos culturais, as batalhas e vitórias não são as mesmas. Graças a essa experiência internacional, levarei esse entendimento comigo enquanto continuo estudando e defendendo as questões das mulheres. (Benner, 2016a, para. 10)

Situações difíceis também surgem em torno da sexualidade. Em 2015, a maioria dos estudantes se viu lidando com os modos como o fundamentalismo religioso afeta o jornalismo, especialmente em uma então recente decisão da Suprema Corte dos EUA sobre o casamento entre pessoas do mesmo sexo. Em seu primeiro dia de estágio, solicitou-se a Erin uma matéria sobre as reações ganesas e estadunidenses à decisão. Seu editor a orientou a usar as mensagens de texto cristãs evangélicas dele como fontes, criando grande tumulto interno, como ela contou em sua postagem no blog (Hampton, 2015). Em seu relatório de estágio, mais tarde, Erin escreveu:

Apesar disso, usei as mensagens, juntamente com várias citações de fontes de notícias americanas sobre as reações mistas à decisão da Suprema Corte, tentando ser o mais imparcial possível. . . Senti que tinha feito um bom trabalho. ... No entanto, quando vi o artigo na primeira página no dia seguinte, meu coração afundou. A manchete dizia: “O 'gayismo' é um insulto à inteligência do Criador, declaram os ganeses".

Embora a manchete não fosse representativa e nunca fosse aprovada em uma publicação confiável dos EUA, Erin ainda estava orgulhosa de ter sido capaz de lidar com a situação de modo que a matéria incluísse igualmente suas fontes. Isso também provocou muitas conversas francas e mutuamente conscientes com seus colegas de trabalho sobre este tema.

A raça constitui uma questão de identidade especialmente desafiadora para os visitantes estadunidenses em Gana, no contexto do ativismo antirracismo e do movimento BLM. Custódio e Gathuo (2020) colocam em primeiro plano o ativismo antirracista e anticolonial em seu estudo de caso da Anti-Racism Media Activist Alliance (Arma), com sede na Finlândia, que combina ativismo midiático com o diálogo freiriano para aumentar a consciência:

Como membros da comunidade universitária na Europa, temos estado do lado privilegiado do espectro em termos culturais e econômicos. Nesse sentido, a compreensão original de Freire de ser oprimido em termos de classe não se aplica a nós. 
Apesar disso, foi somente depois de acessar materiais de mídia e vivenciar o diálogo com pares já engajados em lutas antirracismo que percebemos como o racismo nos afetou e como o sofrimento dos pares também diz respeito à nossa existência. (p. 140)

$\mathrm{O}$ antirracismo constitui um tema duradouro em nosso programa. Gana estava centralmente situada no comércio transatlântico de escravos. Existem cerca de 80 fortalezas e castelos históricos ao longo de sua costa, e muitos foram usados para prender brutalmente escravos capturados, por semanas ou meses, antes de serem enviados para as Américas. Além disso, a independência de Gana, em 1957, coincidiu com o movimento dos direitos civis dos EUA, e a amizade do primeiro presidente do país, Kwame Nkrumah, com líderes desse movimento, motivou numerosas visitas de alto nível, incluindo W. E. B. DuBois, Martin Luther King Jr., Malcolm X e Maya Angelou. Desde essa época, Gana tem atraído cada vez mais afro-americanos que buscam aprender sobre sua herança. O país declarou 2019 o Ano do Retorno, marcando os 400 anos desde que os primeiros escravizados chegaram à América do Norte. Essa narrativa histórica também ajuda a atrair alunos e professores negros para o programa.

Trabalhar com diversos grupos significa trabalhar com consciências variadas em torno de raça, etnia e outras intersecções. Uma vez no local, os alunos lutam com seus sentimentos sobre serem rotulados publicamente de obruni ou oburoni, um termo comum que significa pessoa branca, mas também usado para referenciar qualquer estrangeiro. $\mathrm{O}$ termo não é ofensivo, mas os alunos não se sentem confortáveis em serem chamados dessa forma. Os estudantes brancos muitas vezes tentam conectar seu desconforto à experiência das minorias nos EUA, mas eventualmente e em conversas, percebem que é uma falsa equivalência, como Rachel escreveu:

"Agora eu sei como é ser uma minoria." Como uma pessoa branca em Gana, isso é fácil de dizer. Eu me destaco. Me perguntaram de onde venho. Estou constantemente consciente da minha raça, e é difícil.

Mas essa afirmação não é verdadeira. Especialmente à luz dos recentes e horríveis tiroteios policiais de Philando Castile e Alton Sterling, juntamente com as outras formas de violência racial que ocorrem nos EUA todos os dias, tenho que reconhecer que nunca saberei verdadeiramente como é ser oprimido e desprivilegiado por causa da minha raça.

Como uma "minoria" aqui, eu não sofro a experiência de viés implícito em processos de contratação, nem sinto que as pessoas subconscientemente me ligam ao crime e à violência. Nunca temo pela minha vida na presença da polícia. Pelo contrário, às vezes há um estranho respeito pelos estrangeiros brancos, 
tecido na hospitalidade ganesa. Por exemplo, estou estagiando em uma estação de rádio na capital do país... sem experiência prévia de rádio. Meu privilégio funciona mesmo. (Benner, 2016b, paras. 4-6)

Ao mesmo tempo, afro-americanos e outros estudantes não brancos se sentem decepcionados por também serem considerados obrunis, mesmo durante o Ano do Retorno de 2019. Como Mercedes escreveu,

Éramos Obrunis (estrangeiros), mesmo assim não fomos criados iguais. Eu não me parecia com meus colegas. ... Eu não me encaixo no perfil que os ganeses têm para a "típica garota americana", então fui para o segundo plano em muitos ambientes sociais. Em um lugar onde eu pensei que seria bem-vinda, me senti como uma estranha. (Wright, 2019, para. 12)

As excursões a dois proeminentes castelos de comércio de escravos sempre evocam emoções poderosas - de culpa, raiva, extrema tristeza, confusão e até desespero. Os estudantes não brancos e especialmente os afro-americanos, muitas vezes, consideram essas excursões extremamente dolorosas; mas suas experiências não são uniformes, e é importante encontrar maneiras de deixar todos se expressarem sem julgamento. Juwan, um estudante afro-americano, tinha sido bem-educado sobre o comércio de escravos, mas se viu subjugado pela excursão, lutando para entender como um crime tão massivo contra a humanidade pôde se perpetuar por tanto tempo:

Quero odiar os brancos ... mas, então, você não pode realmente ficar com raiva deles, porque é muito maior do que isso. ... Se o povo africano não tivesse participado, não teria sido tão grande. . . . Não consigo ficar bravo com meu próprio povo.... Só estou furioso com a situação ... havia tantos atores participando dela. (University of Oregon, 2013, 3:12 ${ }^{13}$ )

${ }^{13}$ Vídeo produzido por Ed Madison (University of Oregon, 2013) com as reações

Emoções variadas também podem ser facilmente lidas como desrespeito e falta de empatia. Mercedes, citada anteriormente, escreveu sobre seus sentimentos e seus colegas após a visita ao Castelo de Elmina:

Eu não podia falar durante a visita. Eu não conseguia pensar. Havia uma dor no fundo do meu coração que eu não conseguia explicar. Estava com raiva. Estava magoada. Eu não queria estar lá.

Embarquei no ônibus em silêncio, quando a vida parecia retomar para meus colegas. Eles estavam rindo e brincando, como se tudo pudesse voltar ao normal. Para mim, nada seria o mesmo. (Wright, 2019, paras. 2-3) 
Mais tarde, em nossa discussão, Mercedes foi capaz de compartilhar sua raiva e dor com o grupo maior de uma forma que era bruta e real, e imediatamente mudou o tom da conversação. Donny, um estudante branco, tentou capturar seu senso de culpa, inadequação, vergonha, reconhecimento de privilégios e sentimento de desamparo no momento.

É difícil colocar em palavras as atrocidades que aconteceram no Castelo de Elmina. Como escritor, minhas palavras e as palavras dos outros são, às vezes, tudo o que tenho. Mas hoje, elas parecem de pouco valor e triviais....

Também posso falar sobre meu egoísmo. Sobre minha incapacidade de compreender a grande quantidade de dor ao meu redor. Sobre a enxurrada de pensamentos triviais sobre a minha namorada em casa, sobre meu estágio e meu gato. Para mim, o privilégio existia na minha incapacidade de permanecer atento. Imaginar um mar de rostos perecendo nas mãos dos colonizadores é mais fácil do que imaginar apenas um. Porque se há apenas um, há uma chance de eu reconhecê-lo.

Sim, posso te contar sobre tudo isso, as palavras com gosto insípido e diluído na minha língua. Posso dizer o quanto estou desconfortável escrevendo isso agora. Como a ideia de usar essa experiência como ferramenta de crescimento pessoal parece, ao mesmo tempo, empoderadora e completamente frustrante. (Morrison, 2019a, paras. 6, 12-13)

Outra estudante branca do mesmo grupo, Madeline, refletiu de maneira parecida, mas também enriquecedora, sobre a interseccionalidade de gênero e sobre o imperativo de agir.

Como mulher, imaginei-me aqui pela vontade de um predador estrangeiro e tentei compreender o medo, o desespero e a raiva que milhões de mulheres sentiram aqui, todos os dias, durante 400 anos. Era mais fácil para mim tentar simpatizar com essas mulheres do que enfrentar o fato de que, nas raras ocasiões em que uma mulher branca entrasse nesse castelo, elas não estariam paradas aqui no pátio, mas lá em cima.... O dia da nossa viagem a Elmina foi desconfortável. Não só por causa do calor ou do fedor, mas porque fui forçada a encarar meu privilégio de uma maneira que nunca fiz antes. Não tenho apenas o privilégio branco, que tem um novo significado para mim agora, mas o privilégio de visitar este castelo e experimentar isso eu mesma, e o privilégio que ninguém que jamais viveu aqui teve: saber que isso termina.... E toda essa dor e desenvolvimento não significam nada se não agirmos para garantir que a história não se repita. (Robinson, 2019, paras. 7, 12)

Sempre que emoções poderosas estão envolvidas, aumentam os riscos em ter uma roda de discussão. Como observam Machado e Freire (1998), 
pode haver elementos da terapia de grupo no método dialógico, que atuam para suavizar a culpa do opressor e/ou fazer que os oprimidos se sintam melhor a respeito de sua vitimização (p. xiv). É importante manter-se firmemente focado no projeto político ou na práxis de resistir à injustiça. Há sempre o risco de que as palavras dividam involuntariamente o grupo e afetem negativamente a dinâmica além da discussão e até permanentemente. As palavras também podem ter um impacto desencadeador prejudicial em indivíduos particulares. Ter um forte vínculo de grupo com antecedência é crucial. Ter um grupo extremamente diversificado de apoio mútuo ajuda, assim como convidar diversos colegas (para essa viagem em particular, afro-americanos e ganeses), que podem servir como guias de discussão e iniciar e exemplificar a verbalização de sentimentos complexos e difíceis. Como Freire (1998) recomenda aos instrutores: "O melhor é dizer aos alunos, numa demonstração do que é ser humano e limitado, como se sente naquele momento" (p. 48). Não importa o que aconteça, o risco é real, e nós, como instrutores, precisamos da sabedoria para saber que os riscos significam erros e da humildade para admiti-los e continuar buscando formas de melhorar.

Finalmente, o espaço não permite expandir este tema, mas inúmeros alunos com deficiência participaram do Media in Ghana, e todos contribuíram significativamente. Particularmente memorável é Anais (Annie) Keenon, que possui severa deficiência auditiva ${ }^{14}$. Graças à assertividade de Annie, todos aprendemos a inclui-la nas conversas - por exemplo, garantindo que pudesse ver os palestrantes e/ou tendo alguém mais próximo para repetir os comentários. Como o rádio é o meio mais poderoso de Gana, encorajo os alunos a ouvirem regularmente; mas eu precisava lembrar que Annie não podia fazer isso. Annie fez algumas pesquisas independentes sobre como os ganenses surdos e deficientes auditivos vivem, e ficou preocupada em saber que existem poucos recursos e que os ganeses comumente são enviados a instituições, junto com pessoas com diagnósticos não relacionados, que vão desde a síndrome de Down até paralisia cerebral e a deficiência de mobilidade. Como Annie escreveu:

Só os muito ricos podem se dar ao luxo de enviar seu filho surdo para as escolas residenciais, às vezes para fora do país....

Se eu tivesse nascido aqui, provavelmente só teria me apoiado em sinais e não na minha audição. Poderia nunca ter aprendido a falar ou mesmo a ler. Não teria outras opções. (Keenon, 2011, paras. 9, 11)

Annie se sentiu impotente na ocasião, porém, mais tarde, relatou o que fez como resultado:
${ }^{14}$ Até agora, nenhum candidato apresentou ou divulgou uma deficiência que não pudesse ser contornada, com preparação, pelo programa. 


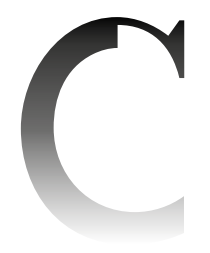

Depois de voltar para os Estados Unidos, não conseguia parar de pensar nas pessoas que conheci. Fiquei determinada a apoiar os direitos das pessoas com deficiência como pudesse. Aos poucos, meus passos se afastaram do jornalismo (embora conseguisse concluir meu curso), na direção do desenvolvimento internacional. Anos depois, me vi trabalhando com os direitos dos deficientes internacionalmente, apoiando homens e mulheres com deficiência em lugares como Indonésia, Mianmar e Haiti. Embora minha vida tenha mudado de direção novamente desde essa época, continuo sendo uma fervorosa defensora dos direitos das pessoas com deficiência - um propósito de vida que é facilmente relacionado àquele verão em Gana. (Keenon, 2018, para. 5)

\section{CULTURA}

A classe, o gênero, a sexualidade, a identidade racial-étnica e a identidade pela deficiência estão obviamente entrelaçadas com várias dimensões da cultura que desafiam estudantes e instrutores, e constituem temas de forte discussão. Aqui, mencionarei brevemente dois deles: o suborno e a religião.

A prática comum do soli, ou seja, fontes que dão aos jornalistas envelopes com dinheiro de transporte em conferências de imprensa e eventos, é de início horripilante, e um tópico comum das postagens do blog e artigos finais. Com o passar do tempo, e no diálogo, os alunos são menos críticos. Embora não abonem o suborno, como tampouco o fazem a Ghana Journalists' Association ou outras organizações profissionais de mídia/comunicação, eles reconhecem que os salários dos jornalistas são terrivelmente baixos, e muitos dependem dessa receita. Também começam a entender que o soli emergiu em parte da cultura da dádiva de Gana. Além disso, embora o soli não seja praticado nos EUA, discutimos as muitas maneiras pelas quais os jornalistas podem ser comprometidos por

${ }^{15}$ Steeves (2006) e Madison e Steeves (2014) discutem o soli com mais detalhes, além dos dilemas éticos relacionados ao plágio. pressões políticas e econômicas, e as muitas questões éticas desafiadoras que os jornalistas em todos os lugares enfrentam ${ }^{15}$.

A maioria dos ganeses são religiosos, e as maneiras pelas quais a religião permeia a vida cotidiana são surpreendentes no início. A religião é flagrante em muitas marcas publicitárias, como em "Obras de Encanamento Nome Divino", "Mantenha a Fé Engenharia", ou "Frigorífico Graça de Deus". Muitos dias de trabalho começam com orações, inclusive em organizações de mídia, empresas de publicidade e relações públicas. Os pregadores são uma presença comum no transporte público. As manchetes noticiosas e as fontes com frequência se referem a Deus e a Jesus, como na manchete mencionada antes, da matéria de Erin sobre casamento gay. Ao mesmo tempo que Gana é predominantemente cristã, os ganeses são tolerantes à diferença religiosa, e cristãos e muçulmanos 
vivem pacificamente lado a lado. As crenças tradicionais também são praticadas, muitas vezes ao lado de práticas cristãs ou muçulmanas. Os eventos governamentais geralmente começam com três tipos de orações: cristã, muçulmana e um derramamento tradicional de libações.

Muitos de nossos participantes se identificam como agnósticos ou ateus. Outros podem praticar uma religião, mas minimamente, ou uma religião incomum em Gana. Os colegas de trabalho muitas vezes confrontam nossos estagiários estudantes com perguntas sobre suas crenças pessoais, e às vezes eles até esperam realizar uma conversão enquanto lideram orações matinais. Como em questões sobre sexualidade, eles aprendem a responder diplomaticamente e de maneiras que às vezes podem levar a conversas surpreendentes, como na experiência de Leigh, depois de marcar "nenhuma" em seu pedido de estágio:

Depois de preencher a documentação, fui apresentado ao meu chefe, que ficou surpreso e intrigado por eu não pertencer a uma religião específica.... Expliquei a ele minha perspectiva sobre religião e minhas crenças espirituais, apesar de temer que ele não me respeitasse por não serem cristãs....

Ele revelou que também tinha muitas perguntas sobre o cristianismo. Ele descreveu... a corrupção em sua igreja, o que o motivou a parar de ir aos domingos....

Meu chefe descreveu sua perspectiva sobre religião, com a porta fechada, em seu escritório, tão silenciosamente que mal era audível. Era evidente que ele estava nervoso por compartilhar suas ideias ambivalentes sobre religião, mas também ficou claro que ele queria falar com alguém com uma perspectiva diferente. (Fahrion, 2019, paras. 3-4, 7)

Da mesma forma, Donny esforçou-se para encontrar um ponto em comum com seu parceiro de reportagem, Melvin, e acabou descobrindo que ele também era cético em relação à religião organizada, uma descoberta que fortaleceu muito a amizade entre ambos (Morrison, 2019b).

As experiências de Leigh e Donny são menos comuns. A maioria dos alunos é convidada por colegas de trabalho para ir à igreja, e até a casamentos, funerais e batizados de bebês. Eles são consistentemente gratos pela oportunidade e geralmente a consideram divertida, muito mais pelos relacionamentos e pela comunidade do que pelo dogma. Luke relatou a experiência de três horas de vários estudantes em uma igreja carismática. Tendo suportado longas e cansativas celebrações na sinagoga de seu país natal, ele estava antecipando algo semelhante, mas descobriu que era exatamente o oposto (Hausman, 2012). Hannah, também judia, era igualmente cética, especialmente por ter tido discussões desconfortáveis no espaço de trabalho sobre sexualidade, mas achou a experiência edificante e conscientizadora sobre o valor do imaterial em Gana. 
Eu estava legitimamente nervosa entrando em um lugar de adoração, o epicentro tanto do poder de conexão da religião como do medo e ignorância, usados para discriminar aqueles que são diferentes.

Mais uma vez, minhas expectativas se mostraram incorretas. Em vez de pregar o ódio, o serviço era uma demonstração entusiasmada de amor e devoção por meio da música....

Embora tradicionalmente tenha sido muito cética sobre a religião organizada, foi ao frequentar a igreja em Gana que comecei a entender por que as pessoas se voltam para a espiritualidade. ... Em vez de me concentrar no ódio e no medo, o que vivi foi o poder da religião para elevar as pessoas e uni-las. ... .

Quando os obrunis estavam partindo, o Profeta nos parou. Nem ele nem sua filha se importavam que nenhum de nós fosse religioso, mas ele queria nos agradecer por vir. Foi angustiante ser diferenciada, mas, mesmo sendo uma estranha, me senti acolhida e aceita. (Steinkoph-Frank, 2015, paras. 8-9, 16-17)

\section{CONSIDERAÇÕES FINAIS}

Evidências de múltiplas fontes ao longo dos anos - discussões em grupo, postagens em blogs, relatórios de estágio, registros de mídia e relacionamentos contínuos com alunos do programa - mostram que, em apenas algumas semanas, os alunos e colegas instrutores têm experiências profundas, até mesmo de mudança de vida, com resultados dependendo de múltiplos fatores: qual o ponto de partida de cada um em relação à diferença e à diversidade; os vínculos formados; a iniciativa pessoal e as reflexões durante e após a viagem. Tem sido gratificante ver os participantes vivenciando um grande crescimento pessoal, ou seja, passando de um estado de profundo choque cultural para um de autoconfiança. Além de um sentimento de crescimento, eles se tornam próximos uns dos outros, desenvolvem relações duradouras com os ganeses; adquirem realizações profissionais; e continuam a refletir criticamente sobre suas experiências. Mais significativo que tudo, os estudantes relatam uma consciência muito mais elevada, até transformadora, das inter-relações humanas e da injustiça social, além de um compromisso de agir. Por exemplo, no final de seu programa, Francis escreveu:

Mais impactante do que qualquer outro momento nesta viagem, foi a experiência doentia de caminhar por castelos de escravos e aprender sobre as atrocidades dos colonizadores europeus nas mesmas salas onde seus crimes ocorreram. Numa época em que há pessoas em prisões no meu próprio país, meu tempo nos fortes me forçou a me comprometer com a causa da justiça e da liberdade em todo o mundo como ativista político. (O’Leary, 2019b, para. 4) 
Muitos também se tornam profundamente comprometidos em construir pontes em suas vidas pessoais e encontrar significado existencial no não material. O pensamento de Freire vai além da pedagogia, como apontam Suzina e Tufte (2020), "é uma visão com um conjunto de princípios e valores fundamentais, que norteiam a constituição de uma ordem social, inspiram uma prática de comunicação e interação social e também servem como guia normativo para a convivência na sociedade" (pp. 412-413). Muitos estudantes do Media in Ghana tentam encontrar palavras para expressar essa realização. Pouco antes da partida, Clare escreveu uma postagem intitulada "Sobre Bondade e Generosidade" (On Kindness and Generosity).

Se alguém me pedisse para dizer alguma coisa que aprendi aqui, daria a eles essas duas palavras.... Quando alguém está comendo no trabalho, mesmo que seja apenas um pequeno lanche, eles sempre olham para mim, apontam para seu milho, pão ou biscoitos e dizem "sirva-se". Quando meus dois colegas descobriram que eu era vegetariana, eles dirigiram 30 minutos comigo, para que eu pudesse experimentar fufu em um restaurante vegetariano....

As pessoas aqui me lembraram de ser mais aberto às amizades, a lembrar de compartilhar, de cuidar daqueles ao meu redor, e de mostrar bondade e generosidade a todos que conheço. (Malone, 2018, paras. 3-4)

Obviamente, programas como o Media in Ghana são limitados. Eles representam o privilégio do Norte Global e são, em grande parte, unidirecionais, contando com a hospitalidade dos ganeses (ver Tilley \& Kalina, 2021). Embora desequilibrado, tentei retribuir o quanto pude ${ }^{16}$. Esses programas também são limitados em escala. Nem todos os alunos são motivados a estudar no exterior e, dos que são, apenas uma fração escolhe um programa em um país em desenvolvimento. Os programas tendem ainda a atender estudantes em duas extremidades do espectro econômico: os com recursos e os que se qualificam para bolsas de estudo baseadas em necessidades. Além disso, há argumentos válidos sobre as mudanças climáticas para evitar viagens aéreas.

Diante dessas realidades, encorajo os alunos que retornam a compartilhar suas percepções com os outros, multiplicando, assim, o impacto do programa por meio de palestras, publicação de artigos e fotos e via ativismo de justiça social pós-viagem e nas relações pessoais cotidianas, como indicado pelos alunos citados. É importante ressaltar que manter relações com alunos do programa constitui uma participação valiosa - ainda que a partir da participação de empoderamento (Tufte \& Mefalopulos, 2009) - e continua a moldar o programa. Vários ex-alunos voltaram a Gana para empregos ou trabalhos como voluntários, às vezes juntando-se ao nosso grupo para partes da viagem. Muitos relataram decisões de mudança
${ }^{16}$ Maneiras pelas quais tentamos retribuir incluem: o recrutamento de inúmeros ganeses para Oregon para a pós-graduação, apoiando estudiosos ganeses visitantes, servindo como examinador externo para a University of Ghana (UG) e recrutando outros colegas para fazê-lo também, e desenvolvendo e encorajando a colaboração de pesquisa. Da mesma forma, os alunos são solicitados a transportar suprimentos solicitados para a UG e levar presentes para seus novos colegas. Também são encorajados a construir colaborações que podem ir além do programa. 
de carreira como resultado, como no caso de Annie (Keenon, 2018). Oliver, que participou em 2004, posteriormente construiu uma carreira em educação experiencial com sede na Cidade do Cabo, África do Sul. Cassie e Kayleigh, participantes em 2007 e 2013, respectivamente, seguiram carreiras em desenvolvimento internacional para a justiça social. Todos os três atribuem essas escolhas diretamente ao Media in Ghana (DeFillipo, 2017; Hagen, 2017; Young, 2017).

Por fim, e dados os limites e críticas da viagem, não é preciso dizer que há outras estratégias para direcionar os alunos e professores de nível universitário rumo à práxis e à conscientização, aplicando conceitos freirianos aos currículos locais domésticos. O crescimento pessoal transformador requer o engajamento em lutas pessoais arriscadas e muitas vezes dolorosas, mas isso pode acontecer de muitas maneiras e diversos locais. Como Freire (1998) sintetiza poderosamente:

Estudar é descobrir; é obter uma compreensão mais exata de um objeto; é perceber sua relação com outros objetos. Isso implica uma exigência de assumir riscos e se aventurar por parte de um estudante, o sujeito da aprendizagem, pois sem isso eles não criam ou re-criam. (p. 21)

\section{AGRADECIMENTOS}

Agradeço a Kisa Clark por suas úteis sugestões. Sou grato às dezenas de estudantes que participaram do Media in Ghana desde 1999. Agradeço também aos colegas que contribuíram significativamente, incluindo Sung Park, Senyo Ofori-Parku, Ed Madison, Chris Chavez e Deb Morrison. Sou grato à School of Journalism and Communication da University of Oregon (UO) por fornecer apoio financeiro a partir das necessidades aos alunos. Os fundos do do Underrepresented Minorities Recruitment Program (UMRP) da Division of Equity and Inclusion da universidade também têm sido um recurso essencial para apoiar diversos alunos e professores na viagem. Pequenas partes deste ensaio são extraídas de um artigo anterior sobre o Media in Ghana (Steeves, 2006), com a permissão do editor. M

\section{REFERÊNCIAS}

Adichie, C. N. (2009). The danger of a single story. TED Conferences. https://bit.ly/3j6ohnY

Amenuti, N. (2019). CNN documentary "Troubled waters": The art of disinformation. Grandmother. https://bit.ly/3y7rc3T

Armor, C. (2013, 23 de julho). Real worlds collided: The burglary. Media in Ghana. https://bit.ly/3khuT27 
Benner, R. (2016a, 2 de agosto). Gender in Ghana. Media in Ghana. https://bit.ly/3ya3a8u

Benner, R. (2016b, 14 de julho). Not all difference is created equal. Media in Ghana. https://bit.ly/3y5zxoF

Berti, A. (2018, 5 de abril). Men account for $90 \%$ of all global millionaires. Verdict. https://bit.ly/3kiSkId

Credit Suisse (2019, outubro). Global wealth report 2019. Credit Suisse Research Institute.

Crenshaw K. (1991). Mapping the margins: Intersectionality, identity politics, and violence against women of color. Stanford Law Review, 43(6), 124-199. https://doi.org/10.2307/1229039

Custódio, L., \& Gathuo, M. (2020). Connections with Paulo Freire's legacy in anti-racism media activist collaboration in Finland. Commons. Revista de Comunicación y Ciudadanía Digital, 9(2), 133-158. https://doi.org/10.25267/ COMMONS.2020.v9.i2.04

DeFillipo, C. (2017, 13 de novembro). [Postagem de blog]. Media in Ghana. https://bit.ly/3mpyspz

Dewey, J. (1944). Democracy and education. The Free Press.

Fahrion, L. (2019, July 21). Religion. Media in Ghana. https://bit.ly/3jabrEY

Freire, P. (1970). Pedagogy of the oppressed [Pedagogia do oprimido] (M. B. Ramos, Trad.). Herder and Herder.

Freire, P. (1974). Education for critical consciousness. Bloomsbury Academic.

Freire, P. (1998). Teachers as cultural workers. Letters to those who dare teach. (D. Macedo, D. Koike \& A. Oliveira, Trad.). Westview Press.

Frye, M. (1983). The politics of reality: Essays in feminist theory. Crossing Press.

Giroux, H. A. (1988). Teachers as intellectuals: Toward a critical pedagogy oflearning. Bergin \& Garvey.

Goulet, D. (1974). Introduction. In P. Freire, Education for critical consciousness (pp. vii-xiii). Bloomsbury Academic.

Gregory, C. R. (2011a, 16 de junho). No postcards here. Media in Ghana. https://bit.ly/3kk2d8L

Gregory, C. R. (2011b, 9 de julho). Heightened contrasts. Media in Ghana. https://bit.ly $/ 3 \mathrm{mlmJsc}$

Hagen, O. (2017, 27 de novembro). [Postagem de blog]. Media in Ghana. https://bit.ly/3zaahPA

Hampton, E. (2015, 30 de junho). First day blues. Media in Ghana. https://bit.ly/3sBOP3m

Hausman, L. (2012, 26 de julho). Church: The three-hour ride. Media in Ghana. https://bit.ly/3sFyGKr 
Higdon, K. (2016, 9 de agosto). A Ghanaian day in 3ish minutes. Media in Ghana. https://bit.ly/2UDs8zk

hooks, b. (1993). bell hooks speaking about Paulo Freire: The man his work. In P. McLaren \& P. Leonard (Eds.), Paulo Freire: A critical encounter (pp. 146-154). Routledge.

hooks, b. (1994). Teaching to transgress: Education as the practice of freedom. Routledge.

Keenon, A. (2011, 13 de julho). Deafness in Ghana. Media in Ghana. https://bit.ly/3sFCon6

Keenon, A. (2018, 10 de janeiro). [Postagem de blog]. Media in Ghana. https://bit.ly/3gnBG9w

Kolb, D. A. (1984). Experiential Learning. Prentice-Hall.

Machado, D., \& Freire, A. M. A. (1998). Forward. In P. Freire, Teachers as cultural workers. Letters to those who dare teach (pp. ix-xix). Westview Press.

Madison, E., \& Steeves, H. L. (2014). Intercultural dialogue through immersive learning: Media internships in Ghana, West Africa. In S. H. Culver \& Kerr, P. (Eds.), Global citizenship in a digital world, MILID yearbook 2014 (pp. 215-226). Nordicom.

Malone, C. (2018, 8 de agosto). On kindness and generosity. Media in Ghana. https://bit.ly/3gkxXt6

Melkote, S. R., \& Steeves, H. L. (2015). Communication for development: Theory and practice for empowerment and social justice. Sage.

Morrison, D. (2019a, 10 de julho). Elmina castle. Media in Ghana. https://bit.ly/2Wkbohj

Morrison, D. (2019b, 29 de julho). My beautiful dark twisted internship. Media in Ghana. https://bit.ly/3ydkwkF

Neal, B. (2016, 4 de agosto). The generosity of Emerge. Media in Ghana. https://bit.ly/3sBjaz8

O'Leary, F. (2019a, 26 de julho). Adjusting. Media in Ghana. https://bit.ly/3goSOLU

O'Leary, F. (2019b, 3 de agosto). Then \& now. Media in Ghana. https://bit.ly/3j4Lua6

Oyěwùmí, O. (1997). The invention of women: Making an African sense of western gender discourses. University of Minnesota Press.

Port, E. (2018). Worldly realities: Women as the other. Media in Ghana. https://bit.ly/3sBooLo

Rasmussen, P. (2013). The folk high school: Denmark's contribution to adult education. In P. Mayo (Ed.), Lifelong learning and the learning society (pp. 219-229). Sense Publishers.

Robinson, M. (2019, 8 de julho). Reflections on Elmina. Media in Ghana. https://bit.ly/3sDEQum 
Shor, I. (1992). Empowering education: Critical teaching for social change. University of Chicago Press.

Steeves, H. L. (2006). Experiencing international education: An internship program in Ghana, West Africa. Journalism \& Mass Communication Educator, 60(4), 360-375. https://doi.org/10.1177/107769580506000405

Steinkoph-Frank, H. (2015, 4 de agosto). Take me to church. Media in Ghana. https://bit.ly/3y6olcD

Stromquist, N. P. (2014). Freire, literacy, and emancipatory gender learning. International Review of Education, 60, 545-558. https://doi.org/10.1007/s11159-014-9424-2

Suzina, A. C., \& Tufte, T. (2020). Freire's vision of development and social change: Past experiences, present challenges, and perspectives for the future. The International Communication Gazette, 82(5), 411-424. https://doi.org/10.1177/1748048520943692

Thomas, P. (1994). Participatory development communication: Philosophical premises. In S. White, K. S. Nair \& J. Ascroft (Eds.), Participatory communication: Working for change and development (pp. 49-59). Sage.

Tilley, E., \& Kalina, M. (2021). "My flight arrives at 5 am, can you pick me up?": The gatekeeping burden of the African academic. Journal of African Cultural Studies. https://doi.org/10.1080/13696815.2021.1884972

Topping, E. (2019, 30 de julho). Parallels of poverty between Ghana and the United States. Media in Ghana. https://bit.ly/3AZykRK

Tufte, T., \& Mefalopulos, P. (2009). Participatory communication: A practical guide. (World Bank working paper n. 170). The World Bank.

University of Oregon (2013). Retracing the footsteps of slaves - Elmina Castle - Ghana, West Africa [Vídeo]. Vimeo. https://vimeo.com/74009506

Wainaina, B. (1992). How to write about Africa. Granta 92. https://bit.ly/2WhzlFB Wright (2019, 10 de agosto). Being the only black girl on a trip to Africa. Media in Ghana. https://bit.ly/3sBTbYi

Yang, C. (2016). Encounters between the 'oppressed' and the 'oppressor': Rethinking Paulo Freire in anti-racist feminist education in Sweden. Race Ethnicity and Education, 19(4), 835-855. http://dx.doi.org/10.1080/13613324.2014.885421

York, C. (2013, 23 de julho). What you learn about life when your life gets stolen. Media in Ghana. https://bit.ly/3kcA6Ix

Young, K. (2017, 3 de novembro). Ghana social marketing foundation. Media in Ghana. https://bit.ly/2WaguNk

Artigo recebido em 23 de junho e aprovado em 12 de setembro de 2021. 